\title{
Research on Construction Features, Dilemma and Improvement Countermeasures of Ecological Environmental Protection in Shanghai
}

\author{
Guodong Yan ${ }^{1, a^{*}}$, Guowei Yan ${ }^{2, b}$ \\ ${ }^{1}$ School of Management, Shanghai University of Engineering Science, China \\ ${ }^{2}$ The School of Accounting and Finance, Shanghai Lixin University of Commerce, China \\ ayanguodong@163.com, b15618592002@163.com,
}

Keywords: Ecological Environmental Protection; ecological civilization construction; Construction Features; Shanghai.

Abstract. The features and dilemma of ecological environmental protection in the districts and counties of Shanghai City, and the countermeasures are presented in this Paper, so as to provide references for relevant governmental departments to improve the ecological environment construction.

\section{Introduction}

In the ranking of China's urban management report (2012), the ranking of Shanghai environment management is comparatively low at $22 \mathrm{nd}$. It mainly because that the three aspects of urban landscaping, "three-waste" processing ratio, and environmental control investment strength are the main bottlenecks of Shanghai environment management; it refers in China's Provincial Ecological Civilization Construction Appraisal Report (ECT2011-2014) that the ecological vitality and environmental quality in Shanghai rank low at 22nd and 25th respectively. It is because that the ratios of the surface water quality, applications strength of pesticide, MSW (municipal solid waste) harmlessness rate, and investment in treatment of environmental pollution in the indexes like GDP are in the downstream levels of the whole country, which shows great contrast with the economic construction and social development. Regional environmental pollution control becomes the key point and difficulty for the ecological construction and urban management field in Shanghai. For this reason, the comprehensive improvement of the regional ecological environment in Shanghai is being continuously increased. It clearly presented that it plans to resolve the environmental pollution problem in key regions in three years, and targeted countermeasure suggestions can be presented only under the premise that the features and dilemma of ecological environmental protection in the districts and counties of Shanghai City are identified. For this purpose, the features and dilemma of ecological environmental protection in the districts and counties of Shanghai City, and the countermeasures are presented in this Paper, so as to provide references for relevant governmental departments to improve the ecological environment construction

\section{Features of ecological environmental protection construction in Shanghai}

\section{Total sewage discharge decreasing sharply, and overall urban quality getting better}

Since 2000, the energy consumption intensity (calculated based on the constant price in 2000) of Shanghai unit GDP has decreased about $45 \%$, and the total discharge volume of main pollutants has greatly decreased. At the end of 2010, the chemical oxygen demand and the total sulfur dioxide discharge volume of the whole city were 0.2198 million tons and 0.3581 million tons respectively, which decreased $27.7 \%$ and $30.2 \%$ than those in 2005, and over fulfilled the emission reduction goal in "the 11th Five-Year Plan". Since "the 12th Five-Year Plan", two indexes of nitric oxide and ammonia nitrogen have been added into pollutants emission reduction based on the original two indexes of sulfur dioxide and chemical oxygen demand. Up to the end of 2014, sulfur dioxide, nitric oxide, chemical oxygen demand, and ammonia nitrogen emissions of the whole city decreased $26.2 \%, 24.9 \%, 15.5 \%$, and $14.5 \%$ respectively on the basis of those in 2010, and the emission reduction goal of national " 12 th Five-Year Plan" has been finished one year in advance. In 2014, the annual mean values of sulfur 
dioxide, nitrogen dioxide, and inhalable particles are the lowest values since 2000, reducing $60 \%$, $26.2 \%$ and $33.6 \%$ respectively. After exceeding $90 \%$ at first time in 2009 , the good rate of the ambient air quality (API) of the whole city increased to $93.7 \%$ in 2012 year by year. After adopting the new air quality standard, the good rate of the ambient air quality (API) of the whole city increased from $66 \%$ in 2013 to $77 \%$ in 2014, the annual average concentration of PM 2.5 increased from 62 microgramme/m3 to 52 microgramme $/ \mathrm{m} 3$, which increased $16.1 \%$, and the ambient air quality (API) of the whole city kept a good level in the Yangtze River Delta urban agglomerations. The surface water ambient quality in Shanghai also turned good on the whole, and black and odorous water in the urban and rural rivers disappeared on the whole. Compared with those in 2000, the chemical oxygen demand, ammonia nitrogen, and total phosphorus concentrations in the water environment assessment section of the whole city decreased $65.8 \%, 62.1 \%$ and $59.6 \%$ respectively in 2014. In 2014, as the main river boundary section of the city, the chemical oxygen demand concentration of Yangpu Bridge of Huangpu River decreased $61.2 \%$ than that in 2000.

\section{Key rectifications of ecological environmental protection construction receiving remarkable effect}

Water source construction and protection obtained important breakthrough, Qingcaosha water source bas been completed on the whole, which changed the situation that Shanghai water source mainly depended on Huangpu River and internal rivers for the long term, planned and adjusted the range of the four major centralized drinking water source protection areas of the city. Moderate and small water intakes merging and adjusting as well as small water plants shutdown enter the ending phase. At present, the water intake quantity of the main raw water intake engineering of the centralized drinking water source has occupied more than $95 \%$ of the water intake quantity of the public water supply and intake quantity of the whole city, and the safety assurance degree of the drinking water has obviously increased. Comprehensive environment improvement of Suzhou River drives the backbone river channels improvement in the central city and "10-thousand channels improvement" in suburbs, black and odorous problems of wide-range river channels were resolved on the whole, the water ecology of the main river channels gradually recovered, important phased objectives have been obtained to water environment improvement of the river channels, and the environment appearances in key and rural areas have been obviously improved.

Comprehensive improvement of key regional environment in the traditional industry areas like Wusong, Taopu, Wujing, etc. has been completed, comprehensive improvement of the regional environments in Jinshanwei chemical engineering centralized area, Baoshan Nanda, etc. has been started, regional pollution contradiction and environment petition have been effectively relieved, and a new development road combining regional comprehensive improvement and overall transformation has been gradually created. Improvement of the key pollution sources which influence landscape and near-surface air quality obtained substantial progress, standardized reconstruction or clean energy substitution of more than 9000 coal-fired boilers has been accumulatively completed, and National Stage V Motor Vehicle Emission Standards have been implemented in advance. Comprehensive improvement of agriculture and rural environment are gradually carried out from points to the entire area, village reconstruction has been carried out to 930 villages accumulatively with 0.38 million rural households; the total quantity of the application of the chemical fertilizer and pesticide decreases year by year, and accumulatively 1.61 million tons of organic fertilizer and 4.84 million mu.time have been promoted; comprehensive treatment of beasts' and birds' fecaluria, and prohibition of straw burning have achieved positive progress, and the rate of multipurpose utilization of straw reached more than $91 \%$.

\section{Optimized development of environmental protection boosting transformation and upgrading}

With the breakthrough of the strengthening of the energy conservation and environmental protection standards as well as improvement and upgrading of key areas, the industrial pollution prevention mode composed by the key points of pollution control, structure adjustment and technical upgrading, overall adjustment and transformation, integrated regulation and transformation has been gradually explored in Shanghai. Stick to the strategies of "suppressing the second industry and 
developing the third industry" in the central urban area and "three-centralization" in suburbs, and the new pollution-carrying industrial projects outside the 104 industrial area blocks are eliminated on the whole, and the environmental infrastructure construction and environmental management systems in the industrial area have been further improved. Based on it, with the breakthrough of improvement and upgrading of key areas, it drives the traditional industry structure upgrading and enterprises technical reconstruction. In the past 15 years, shutdown and adjustment of more than 6000 pollution enterprises or production lines have been completed in the whole city. Meanwhile, the pilot projects in the fields of low carbon, recycling economy, and clean production in industry, agriculture, community, etc. have been gradually developed in Shanghai. Since 2004, accumulatively more than 2000 enterprises have participated in the clean production examination. Jinqiao Export Processing Area, Xinzhuang Industrial Area, etc. have been constructed to be national ecological industry demonstration gardens. "Low-carbon Expo" has obvious demonstration and driving effects, and clean and renewable energies are greatly developed. Installed generating capacities of wind power, photovoltaic power, and biomass power gradually increase in the whole city, and the energy structure continuously improves in the whole city. From 2000 to 2013, the ratio of coal in the primary energy source decreases from $65.5 \%$ to $41.4 \%$, and the ratio of natural gas increase from $0.6 \%$ to $9.3 \%$.

\section{Upgrading of system guarantee enhancing the improvement level}

Environmental legislation system has been comprehensively formed in Shanghai. Shanghai Environmental Protection Regulations has been revised, local laws and rules of Shanghai Municipal Drinking Water Sources Protection Regulations, Shanghai Regulations for the Control of Air Pollution, Shanghai Social Life Noise Pollution Prevention Measures, etc. are presented, and local environmental standards and codes like Semiconductor Industry Pollutant Discharge Standards, Lead Battery Industry Air Pollutants Emission Standards, etc. are formulated. The environmental economic policy is continuously innovated in Shanghai, a series of subsidy policies like subsidy on sewage collection pipe network construction in suburbs, sewage treatment charging system, excessive reduction incentives, differential electricity prices of desulfurization power plant, clean energy substitution of coal-fired boiler, greening forestry construction, shutdown of livestock farming and poultry grazing land, etc. are implemented, and price leverage effect works via the measures of increase of water price, electricity tariff, pollution charges standards, etc. Environmental quality monitoring system and pollution source monitoring system are being continuously improved in Shanghai, the environmental quality monitoring system for water, atmosphere, noise, radiation covering the whole city has been formed on the whole, and it becomes the first batch of national cities which realize normalized monitoring and distribution according to the new standards of air quality.

\section{Increasing improvement of the overall level of ecological civilization construction}

China's Provincial Ecological Civilization Construction Appraisal Report (ECT2011-2014) has released China's ecological civilization indexes for the successive four years. It shows in the analysis data that the overall ecological civilization level had increasingly increased in Shanghai from 2003 2012, wherein: it slightly decreased during $2003 \sim 2004$, which was mainly caused by the regression of the ecological vitality and environmental quality; the regression during $2009 \sim 2010$ was resulted from the decrease of ecological vitality and social development; the progress index reached up to $52.21 \%$ during 2005 2006, which was due to the high progress index of the environmental quality in this year; the overall progress index was $27.55 \%$ during $2008 \sim 2009$, which benefited from the obvious improvement of ecological vitality; while the total progress index was $-3.20 \%$ during $2011 \sim 2012$, which was mainly due to the negative growth of environmental quality and coordination degree, especially that the progress index of the environmental quality index reached double-digit negative growth. Specifically, during $2011 \sim 2012$, ecological vitality increased $0.03 \%$, ranking 25th in the whole country; environmental quality improved $-1.60 \%$, ranking 26th in the whole country. The overall progress index situation of Shanghai during $2011 \sim 2012$ was not good enough, which is shown in Fig. 1. 


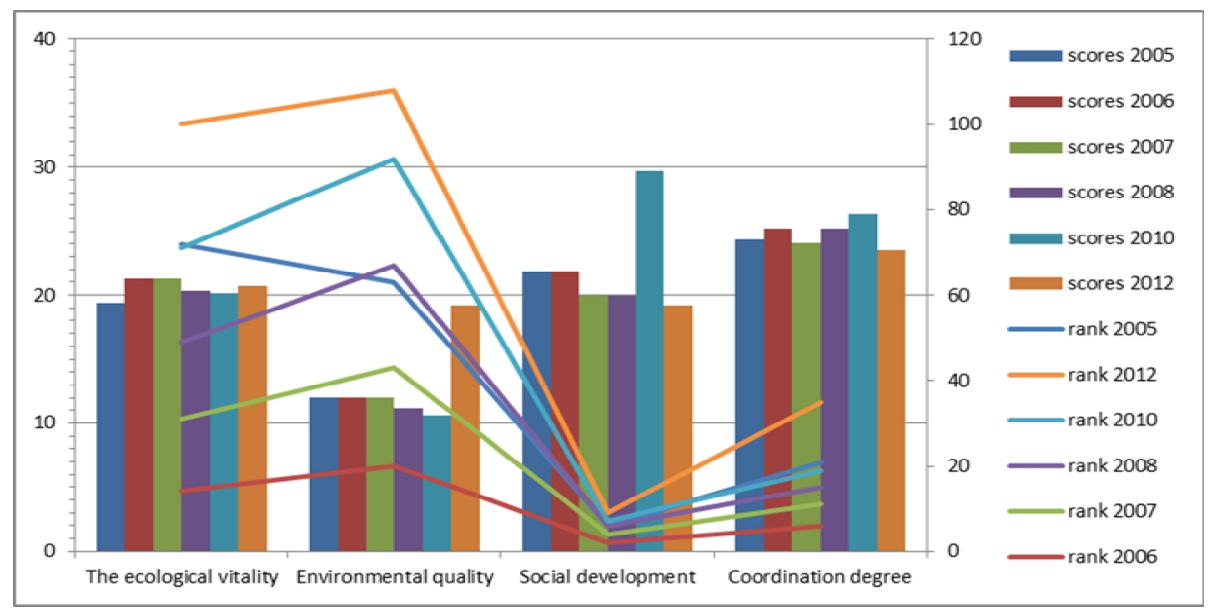

Fig. 1. Shanghai ecological environmental quality assessment results

\section{The imbalanced development of ecological environmental protection and construction in Shanghai}

\section{Slight rise of ecological vitality development}

During $2003 \sim 2012$, the ecological vitality showed overall upward trend in Shanghai, but the rising speed slowed down to some extent. Wherein: it had the greatest rising range during 2008 2009, and had the greatest regression range of 19.91\% during 2009 2010, it was roughly balanced during 2011 2012, the greening coverage rate in the completed area slightly decreased, while the forest quality index ranked comparatively low. With the construction strengthening on aspects of urban forest development, coast protection forest construction, wetland conservation, and suburb plain greening, etc. in Shanghai, the overall level of the ecological vitality in the whole city comprehensively increased. Compared that in 2010 with that in 2013, the forest coverage rate increased 1.5 times, and the greening coverage rate in the completed area increased steadily. In Dec. 2012, Shanghai Afforestation and City's Appearance Management Bureau presented the goal that "in 2015, the 0.42 million $\mathrm{m} 2$ of forest growing stock is going to be increased, and the possession ratio of natural wetland keeps more than $30 \%$ ". All these tasks are the direction and point of strength for ecological vitality improvement during the process of ecological civilization construction in Shanghai at present.

\section{Significant progresses of environmental quality development}

The environmental quality in Shanghai progressed significantly during $2003 \sim 2010$. Under the situation of the generally regressed environmental quality of all the provincial capitals (only 4 provinces progressed in the whole country), the progress rate of Shanghai reached $31.46 \%$, ranking the 1 st in the high progress indexes ranking list. In the progress indexes of the years, it had the greatest progress range during 2005 2006, reaching $227.69 \%$. Shanghai continuously kept the advantage of zero water and soil wastage rate, ambient air quality improved to some extent, superscale of fertilizer application was in the middle-upper reaches level, but the surface water quality and pesticide applications were still in the middle-lower reaches level of the whole country. The remarkable improvement of the environmental quality in Shanghai is mainly due to the effective improvement of surface water quality and continuously improvement of the ambient air quality. During the rapid economic development process in Shanghai, rich water resources were seriously polluted. In 2004, the length ratio of the main rivers with Grade I III water quality nearly doubled compared that in 2003, rising from $13.09 \%$ to $26 \%$, but its absolute percentage was still low. The situation of ambient air quality is comparatively good, the ratio of number of days with the air quality better than second level weather steadily increased, which have exceeded $90 \%$ at present. in certain degree, the large annual improvement of the ambient air quality in Shanghai cannot be achieved without the formulation and implementation of the rules and regulations of "The 12th Five-Year Plan" of Air Pollution Control in the Key Areas, the Division and Implementation Plan for "Non-coal Combustion Area" and "Near Non-coal Combustion 
area" in Shanghai City (2011 2015), and Development Planning of Motor Vehicle Environmental Protection Inspection Institutions in Shanghai City, etc.

\section{Countermeasures and suggestions for accelerating ecological environmental protection construction in Shanghai}

\section{Accelerating the establishment of joint prevention and control mechanism for atmospheric pollution}

After Joint Prevention and Control Technology Demonstration Area for Atmospheric Pollution in Pearl River Delta, Joint Prevention and Control Technology Demonstration Area for Atmospheric Pollution in Yangtze River Delta was organized and set up in Shanghai to operate and cover the mechanisms of air quality management system in Yangtze River Delta, so as to realize the monitoring and prediction as well as rapid response to the change of ambient air quality. Meanwhile, a series of major planning and plans were researched and presented to release the atmospheric control regulations, implement "haze control" accountability mechanism, and set the joint prevention and control rules specific to strong atmospheric pollution. Environmental enforcement agencies should eliminate the negative interference of local interest groups according to the vertical management mode, expand the disclosure channels of the particulate matters like PM10 and PM2.5, etc., and establish and complete the accountability system for the excessive emission of air pollutants.

\section{Actively exploring multi-channel financing mechanism}

Give full play to the function of the social force and private capital, explore and set up ecological compensation funds, and encourage all kinds of non-governmental organizations (NGO) to participate in the ecological protection projects. In order to make up the insufficient compensation funds, it is suggested to further expand the financing channels, explore and set up ecological compensation funds, and set up the complete funds operating mechanism from capital raising, capital operating, to supervisory mechanism with the contribution of NGO or private capitals. On the other hand, the effect of environmental protection NGOs come into play on aspects of water source ecological protection, etc. in recent years. For example, ecological restoration project of Dalianhu Wetland jointed initiated by Qingpu District Government, Shanghai Afforestation and City's Appearance Management Bureau, and WWF in 2008 had become a successful demonstration combining wetland restoration, ecological agriculture, community participation and long-term management via wetland recovery and water quality purification for one year. This kind of mode is suggested to be greatly promoted; "government sets up the stage for the performance by NGO"; fully play the active functions of the social organizations like NGO, etc., so as to enable it to be the beneficial supplement for accelerating the rapid development of water source ecological development in Shanghai.

\section{Strengthening the construction of environmental enforcement capacity}

The district and county governments should strengthen the leaders working mechanism for the special environmental protection action lead by relative leaders, complete all the working systems for collaboration among the departments, strengthen the supervision to the key areas, key industries, and key enterprises, circulate criticism notices and communicate with the responsible persons for poor inspection and improvement, as well as poor implementation of investigation on environmental illegal activity; insist on the strict regulations to control the pollution, resolutely implement pollutants discharge reduction responsibility, and intensify the responsibility investigation. According to Assessment Method for Reducing Emissions of Total Amount of Main Pollutant during the Period of "12th Five-Year Plan", the Environmental Protection Department and other relative departments adopted punishment measures to the districts, counties, and enterprises with prominent problems specific to the total discharging reduction situations in Shanghai in 2014, such as: suspend the EIA approval of construction projects with newly added sulfur dioxide and nitrogen oxide emissions, carry out supervision, and order rectification within a definite time for the sewage treatment plants which failed to carry out qualified rectification or failed to complete the rectification tasks, suspend the EIA approval of construction projects with newly added chemical oxygen demand and ammonia nitrogen emissions, and suspend the release of the national construction funds of relevant projects. Actively explore innovative enforcement working mode, further complete the joint enforcement, regional 
enforcement, and cross enforcement systems, so as to guarantee the qualified supervision and inspection, investigation and treatment, and rectification. Actively promote public participation and supervision by public opinions, encourage the masses to report illegal environment activities, seriously examine the environmental problems reflected by media, network and the masses, and timely report and release the results of the investigation and treatment to the media.

\section{Acknowledgements}

This work was financially supported by reform and development of Yangtze river delta in 2014 research project of China executive leadership academy. Pudong. "Yangtze river delta region ecological civilization system innovation research" (CELAP2014-YZD-10), the Shanghai government decision-making consultation project "based on Shanghai cruise economy contribution evaluation index system research" (2014-Z-J06-B), Shanghai engineering technology university curriculum construction project" the tourism consumption behavior"All English construction (K201403007), We are grateful to their valuable comments.

\section{References}

[1] Johan Jansson and Agneta Marel.Green consumer behavior:determinants of curtailment and eco-innovation adoption.Journal of Consumer Marketing Vols 27,2010

[2] Ri Jiberman, et. al. Deferent approaches to assessment of design and management of sustainable urban water system. Environment Impact Assessment Review, 2000, 129 (3): 333-345.

[3] Xiangrong Liu, in, Ecological Civilization Development Strategy Study, People's Publishing House, Beijing, 2013.

[4] Ecology Civilization Research Center of Beijing Forestry University, in Chinese Provincial Eco-civilization Construction Evaluation Report, Social Sciences Academic Press, 2013.

[5] Lang Zhang: The Change of Shanghai Ecological Resources Use Mode Promote Green Space System Mutation. Territory \& Natural Resources Study (2013) 